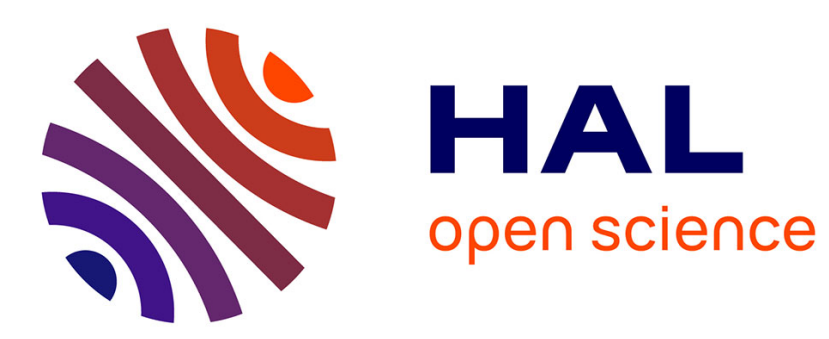

\title{
Optothermal pulse response of human skin : results of mathematical modelling
}

\author{
K. Giese, Th. Siebert, K. Kölmel
}

\section{To cite this version:}

K. Giese, Th. Siebert, K. Kölmel. Optothermal pulse response of human skin: results of mathematical modelling. Journal de Physique IV Proceedings, 1994, 04 (C7), pp.C7-457-C7-460. 10.1051/jp4:19947106 . jpa-00253158

\section{HAL Id: jpa-00253158 https://hal.science/jpa-00253158}

Submitted on 1 Jan 1994

HAL is a multi-disciplinary open access archive for the deposit and dissemination of scientific research documents, whether they are published or not. The documents may come from teaching and research institutions in France or abroad, or from public or private research centers.
L'archive ouverte pluridisciplinaire HAL, est destinée au dépôt et à la diffusion de documents scientifiques de niveau recherche, publiés ou non, émanant des établissements d'enseignement et de recherche français ou étrangers, des laboratoires publics ou privés. 


\title{
Optothermal pulse response of human skin: results of mathematical modelling
}

\author{
K. Giese, Th. Siebert and K. Kölmel* \\ Institut für Medizinische Physik und Biophysik, Georg-August-Universität, Gosslerstrasse $10 f$, \\ 37073 Göttingen, Germany \\ * Hautklinik, Georg-August-Universität von-Siebold-Strasse 3, 37075 Göttingen, Germany
}

\begin{abstract}
The outermost layer of the stratified skin tissue is the 10-15 $\mu \mathrm{m}$ thick horny layer, the thermal and optical properties of which strongly depend on ambient conditions. The pulse response of temperature elevation following the absorption of a short light pulse is derived and discussed.
\end{abstract}

\section{INTRODUCTION}

The epidermis provides the permeability barrier between the organism and the environment. Experimental methods which can be used (1) for studying physiological changes of human skin in response to variations of ambient conditons and (2) for investigating the penetration of topically applied drugs into the skin find wide spread interest in dermatological research. Optical techniques have been successfully utilized for such measurements [1]. Besides remittance and fluorescence spectroscopy, especially the method of photothermal spectroscopy is employed. This procedure, which allows depth resolved in vivo measurements, makes use of the strongly dispersive propagation of thermal waves, which are generated inside the medium under test by absorption of intensity modulated light and detected at the surface.

In photothermal experiments aimed at the determination of optical and thermal properties of skin in vivo, the modulation of surface temperature in most cases is measured by use of methods which make use of the photoacoustic effect or of the mirage effect. The former method requires an open-ended cell to be pressed against the skin surface [2], the latter measures the deflection of a laser beam passing the skin at automatically controlled distance [3]. Recently the technique of optothermal transient emission radiometry has been shown to be a promising new tool for the characterization of human skin, with potential for investigating skin in vivo at locations which are hardly accessible to the other photothermal techniques [4]. This method makes use of the increase in thermal infrared radiation induced by the absorption of a short light pulse. The thermal infrared radiation emanates from a depth range beneath the skin surface depending on the infrared transparency of skin. With detectors operating at IR-C-wavelengths, the radiation approximately reflects the surface temperature [5]. Therefore the data on optical and thermal properties of skin, obtained by the different techniques either in the frequency or in the time domain, should be comparable. Due to the lack of a satisfactory description of the pulse response curves and, correspondingly, of extraction of relevant skin parameters from the signals, up to now the potential of transient emission radiometry has not been realized.

In this paper we report on the mathematical modelling of pulse response signals to be obtained by broad band detection of the surface temperature. The physical basis of the model finds support already in the description of results of experiments performed in the frequency domain. In this model the outermost layer of the skin, the 10 to $15 \mu \mathrm{m}$ thick horny layer, is considered as a layer 
the water content of which strongly depends on ambient conditions. Dry stratum corneum shows comparatively low values of thermal diffusivity $\Lambda$ and thermal inertia $K[6]$. The underlying viable epidermis, about 100 to $150 \mu \mathrm{m}$ thick, has thermal properties like typical water rich tissues. At the transition between both regions, the thin stratum lucidum serves as an effective barrier for the diffusion of bodily water into the horny layer [7]. The thermal properties of the dermis are mainly determined by the blood circulation.

\section{PHYSICAL CONSIDERATIONS}

For the frequency domain, evaluation of the surface temperature of a medium with depth dependent optical and thermal properties a multi-layer model has been discussed in detail elsewhere [8]. The thermal mismatch between successive layers gives rise to multiple reflexions of thermal waves within the structure. The multi-layer model is of interest especially for describing photothermal data in case of spatial gradients of optical properties due to the diffusion of light absorbing drugs [1]. To take into account the main features of untreated skin, the description of the pulse response function requires at least a two-layer model. If irradiated with a short light pulse of energy $\mathrm{E}$ per unit area at time $\mathbf{t}=\mathbf{0}$, the temperature elevation at the sample surface is given by

$$
\begin{aligned}
\vartheta(t)= & \frac{\beta E}{\rho C}\left\{\sum_{n=0}^{\infty} r^{n} e^{2 n a+u} \cdot\left[\operatorname{erfc}\left(\sqrt{u}+\frac{n a}{\sqrt{u}}\right)-\operatorname{erfc}\left(\sqrt{u}+\frac{(2 n+1) a}{2 \sqrt{u}}\right)\right]\right. \\
& +\sum_{n=1}^{\infty} r^{n} e^{-2 n a+u} \cdot\left[\operatorname{erfc}\left(\sqrt{u}-\frac{n a}{\sqrt{u}}\right)-\operatorname{erfc}\left(\sqrt{u}-\frac{(2 n-1) a}{2 \sqrt{u}}\right)\right] \\
& \left.+\sqrt{q}(1+r) e^{-a} \sum_{n=0}^{\infty} r^{n} e^{(2 n+1) a \sqrt{q}+q u} \operatorname{erfc}\left(\sqrt{q u}+\frac{(2 n+1) a}{2 \sqrt{u}}\right)\right\} \\
\text { with } \vartheta(t) \rightarrow \frac{\beta E}{\rho C}\left(1-\sqrt{4 \beta^{2} \Lambda t / \pi}\right) \text { at times } t<<\ell^{2} / \Lambda & \text { at times } t>>\ell^{2} / \Lambda
\end{aligned}
$$

On the right hand side of eqn. (1) the parameter $u=\beta^{2} \Lambda t$ has been used for brevity. It is $\beta$ the absorption coefficient, $a=\beta \ell$ the absorbance of the horny layer of thickness $\ell$ and $\rho C$ its volumetric heat capacity. $r=\left(1-\sqrt{K_{s} / K}\right) /\left(1+\sqrt{K_{s} / K}\right)$ is the reflection factor of thermal waves at the interface between horny layer and viable epidermis (index $s$ ), depending on the respective thermal inertia, $\mathrm{K}$ and $K_{s}$, and $q=\beta_{s}^{2} \Lambda_{s} / \beta^{2} \Lambda$. $\operatorname{erfc}(\mathrm{x})$ denotes the complementary error function of argument $x$. Assuming both layers to have the same thermal and optical properties, eqn. (1) simplifies to the relation

$$
\vartheta(t)=\frac{\beta E}{\rho C} e^{\beta^{2} \Lambda t} \operatorname{erfc}\left(\sqrt{\beta^{2} \Lambda t}\right)
$$

\section{DISCUSSION}

Time domain experiments performed 20 years ago by Kraning [9] were focused on the long time behaviour of the pulse response of temperature elevation, which according to eqn. (2b) reflects the magnitude of thermal inertia $K_{s}$. By his measurements most reliable data of the thermal inertia of epidermal tissue were obtained. The tail of the response curve does not depend on the depth range of heat deposition as determined by the inverse of optical absorption coefficient. This behaviour corresponds to the photothermal saturation to be observed in frequency domain experiments at low modulation frequencies. Since the thermal inertia of viable epidermal tissue shows only small 
variations, for comparing response curves of treated and untreated skin, or of skin of different localizations, the tail seems to be most suitable for a normalization procedure.

At short times the situation is more complex. The initial value of temperature elevation is mainly determined by the optical absorption coefficient of the horny layer, which depends on wavelength and is particularly large in the ultraviolet spectral region. Besides this, the absorption depends on water content and, in case of penetration studies, on the optical properties of applied drugs. Against this, the volumetric heat capacity is of lower interest, as this quantity shows only small alterations with skin condition. Figure 1 shows response curves as obtained from relation (1) by use of different values of horny layer absorbance and constant thermal parameters. At UV-B-wavelengths, for dry stratum corneum the scaling factor $\beta^{2} \Lambda$ of the time axis is of the order of magnitude of $10^{3} \mathrm{~Hz}[10]$.

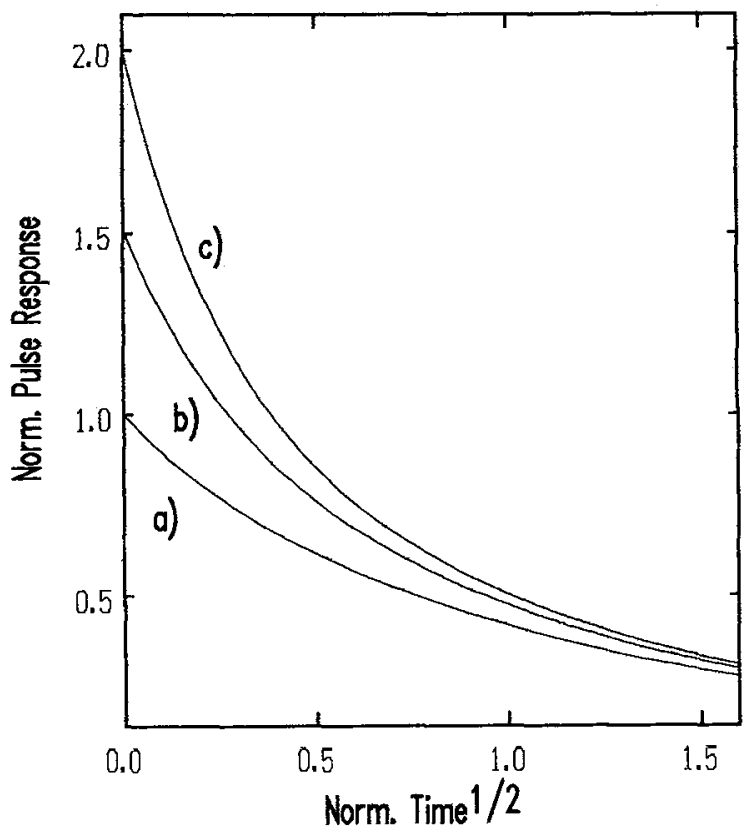

Fig. 1: Normalized response curves of surface temperature after irradiation of skin by a short pulse of ultraviolet light, which is absorbed in the horny layer. Eqn. (1) has been evaluated by assuming the horny layer absorbance $a=$ $\beta \cdot \ell$ to be 2,3 and 4 in curves a), b) and $c$ ), respectively. Normalization was performed by use of the respective parameters characterizing curve a. Constant values are used for the thermal parameters.

The horny layer can considerably enlarge its thickness by uptake of water. Apart from a slight hypsochromic shift of the keratin absorption band and changes in scattering properties [11], the absorbance $\beta \ell$ of stratum corneum remains constant with swelling, whereas the absorption coefficient decreases by water uptake [10]. The magnitudes of thermal diffusivity and the thermal inertia of stratum corneum increase with water content in parallel to that of heat conductivity $[6,9]$. In the scaling factor $\beta^{2} \Lambda$ these dependences of optical and thermal properties on water content partly cancel each other, however, as the resulting effect a pronounced decrease with water content is observed [10].

\section{References}

[1] Sennhenn B., Giese K., Plamann K., Harendt N. and Kölmel K., Skin Pharmacol. 6(1993)152160

[2] Kölmel K., Sennhenn B. and Giese K., J. Soc. Cosmet. Chem. 37(1986)375 385

[3] Plamann K., Giese K., Sennhenn B., Harendt N. and Kölmel K., "In vivo evaluation of the human skin permeation of topically applied light absorbing agents by a mirage effect spectrometer", Photoacoustic and Photothermal Phenomena III, Doorwerth 26-30 August 1991 (Springer-Verlag, Berlin, 1992) pp. 92-94 
[4] Bindra R. M. S., Ecclestion G. M., Imhof R. E. and Birch D. J. S., "Optothermal characterization of human skin", Photoacoustic and Photothermal Phenomena III, Doorwerth 26-30 August 1991 (Springer-Verlag, Berlin, 1992) pp. 95-99

[5] Health Council of the Netherlands, Committee on Optical Radiation, "Optical radiation. Health-based exposure limits for electromagnetic radiation in the wavelength range from $100 \mathrm{~nm}$ to $1 \mathrm{~mm}$ ", The Hague: Health Council of the Netherlands, 1993, Report 1993/09E

[6] Werner U., Giese K., Sennhenn B., Plamann K. and Kölmel K., Phys. Med. Biol. 37(1992)2135

[7] Proksch E., Ärztl. Kosmetol. 19(1989)424-443

[8] Giese K., Nicolaus A. and Kölmel K., Med. Biol. Eng. Comp. 23, Suppl. 1(1985)378-379

[9] Kraning K. K., J. Appl. Physiol. 35(1973)281-287

[10] Giese K. and Kölmel K., "A photoacoustic hydration study of human stratum corneum", Photoacoustic and Photothermal Spectroscopy, Paris 5-8 April 1983 (Les Editions de Physique, 1983) pp. 373-378

[11] Kölmel K., Sennhenn B. and Giese K., Br. J. Dermatol. 122(1990)209-216 